\title{
Formula one: best is no formula
}

\author{
Andrew Bush ${ }^{1,2}$ and Adnan Custovic ${ }^{2}$ \\ Affiliations: ${ }^{1}$ Royal Brompton Hospital, London, UK. ${ }^{2}$ Imperial College, London, UK. \\ Correspondence: Andrew Bush, Dept of Paediatric Respiratory Medicine, Royal Brompton Harefield NHS \\ Foundation Trust, Sydney Street, London SW3 6NP, UK. E-mail: a.bush@rbht.nhs.uk
}

@ERSpublications

Breast is best; formula is worst: in between, there may be a typically British compromise! http://ow.ly/o1to309Wf6F

Cite this article as: Bush A, Custovic A. Formula one: best is no formula. Eur Respir J 2017; 49: 1700105 [https://doi.org/10.1183/13993003.00105-2017].

\begin{abstract}
"Begin at the beginning," the King said, very gravely, "and go on till you come to the end: then stop" (Lewis Carroll, Alice in Wonderland). Sometimes, however, ignoring this excellent advice may be beneficial to the editorialist. So, starting at the end, how do patients reach a point of premature airflow obstruction (or chronic obstructive pulmonary disease (COPD) to those who think that an arbitrary physiological ratio in spirometric measures of lung function is a disease, even though it may be within the normal range for age)? For a long time, the prevailing view was that most individuals achieve normal or near-normal maximal lung function in early adult life, following which those who go on to develop COPD suffer a rapid decline as a result of various environmental exposures (predominantly smoking) [1]. However, the crucial importance of the level of lung function attained in early adulthood has been highlighted in a recent study, which demonstrated that the level of lung function in early adult age, at its physiological plateau, is as important in the genesis of COPD as its rapid decline in later years. The manuscript describes two trajectories to a reduced forced expired volume in $1 \mathrm{~s} /$ forced vital capacity (FEV1/FVC) ratio [2]. In the first, there was failure to reach the normal plateau of maximally attained spirometric function in early adulthood (at age 20-25 years), with a subsequent normal rate of decline. In the second, the group attained a normal plateau, but declined more rapidly. Individuals who did not reach the expected lung function plateau had a $26 \%$ chance of going below the "magic" FEV1/FVC of $70 \%$, while among those in whom a normal plateau was reached, the risk was $8 \%$. Importantly, both trajectories contributed equally to the community burden of COPD. Of note, neither this nor any of four other major studies of decline in lung function with age [3-6] managed to find consistent associates of accelerated lung function decline (including smoking, politically unpalatable though this statement may be). Indeed, data from the CAMP [7] and Tucson cohort (which identified a group of individuals with a persistently low lung function trajectory between ages 11 and 32 years, which comprised nearly 1 in 10 participants) [8] confirmed that abnormal lung growth patterns are established early in life. Clearly, starting at the end turns the spotlight firmly on the beginning: early life, which is where efforts at prevention of COPD must be focused if they are to have any chance of success.
\end{abstract}

The evidence is mounting that genetic and early environmental effects and their interactions are pivotal in causing abnormal lung growth, but also an accelerated decline of spirometry decades later. Based mostly on cross-sectional data, several factors in childhood, including obesity [9], lower socioeconomic status [10], pre-term birth [11], exposure to residential soil silt [12], rhinovirus infection [13], cigarette smoking and short duration of breast feeding [14] have been reported to be associated with diminished adult lung function. For example, the ECFS study identified five indices of childhood deprivation as predictors of reduced $\mathrm{FEV}_{1}$, accelerated decline in FEV1, and increased risk of COPD. These were maternal, paternal and childhood asthma; maternal smoking; and severe childhood respiratory infections [15]. Underlying these risk factors are a mix of other environmental exposures, genetic factors and their interactions, operating

Received: Jan 162017 | Accepted after revision: Jan 172017

Conflict of interest: Disclosures can be found alongside this article at erj.ersjournals.com

Copyright CERS 2017 
ante- and post-natally, and probably even trans-generationally $[16,17]$. There are numerous candidate genes; for example, ADAM-33 is important in antenatal airway branching morphogenesis [18], with effects being modulated by maternal atopy [19], and polymorphisms are related to preschool lung function [20] and also to an accelerated decline in lung function [21]. Genetic variants in VEGF-A are associated with low lung function in childhood, and this effect may persist into adulthood [7], while polymorphisms in CC-16 are not only associated with worse childhood lung function and failure to attain the normal plateau, but also accelerated decline in adult life [22].

The long-term adverse environmental effects of nicotine exposure and environmental pollution are well known, and have recently been reviewed $[23,24]$. That adverse effects can operate ante- and post-natally is well known, with the COPSAC group [25] suggesting that $60 \%$ of airflow obstruction at age 7 years is post-natal and $40 \%$ antenatal, offering at least the potential to move from hand-wringing to action. Such action hitherto meant continued assaults on the tobacco and e-cigarette industries, and continued attempts to engage politicians in reducing air pollution, but not much else. To move forward, we desperately need to understand the mechanisms of the early inception of respiratory morbidity and diminished lung function. It must be emphasised that the factors responsible for disease onset are very different from those responsible for disease persistence and severity (which is indirectly confirmed by early pathological studies [26], and the abject failure of inhaled corticosteroids to modify the natural history of asthma and wheezing in childhood [27-29]).

The role of breast feeding in terms of respiratory benefits to the baby and its effect on allergy has been controversial, whatever the undoubted merits of the practice in other health domains. In this issue of the European Respiratory Journal, the CHILD study investigators report the beneficial effects of breast feeding on wheezing illness in infancy among the children of asthmatic mothers [30]. The strengths of the study include the large numbers of babies studied, and the prospective recording of symptoms and feeding practices. The conclusions are greatly strengthened by the demonstration of a dose-response effect; the longer the infants were breast fed, the lower was the prevalence of wheezing, and those exclusively breast fed also wheezed less. Importantly, it was the introduction of formula milk, rather than complementary food that abrogated the protective effects of breast feeding. The potential effects on allergy are also important, and in this regard the data are reassuring. The early introduction of complementary foods to prevent allergy did not interfere with the protective effects of breast milk on wheezing illness. Mothers are uniquely privileged to be in receipt of all sorts of usually mutually contradictory and hopelessly impractical advice from all and sundry, and whether adding in complementary foods is a good thing or not was not addressed by this study. Dare it be suggested that, in the absence of hard evidence, mothers should be left to their own devices when it comes to the introduction of allergenic foods?

There are, of course, difficulties in the interpretation of these data. The maternal asthma diagnosis may be questionable, because diagnosing asthma and wheezing disorders is difficult and many adults and children are misdiagnosed [31, 32]. Secondly, the word "wheeze" is used notoriously imprecisely by parents [33-36], and studies relying purely on questionnaires may be misleading. It is a pity that the authors did not have access to video-questionnaires to bolster the diagnosis of wheeze $[34,35]$. It is also by no means clear what the first-year respiratory illnesses betoken. Their implications and epidemiology are highly variable [37], and it is likely that the underlying pathology is very different from childhood and adult asthma [26]. The trend for a stronger protective effect of breast feeding among boys is interesting but merely a trend, and should not be over-interpreted. More prolonged follow-up of this cohort is needed to understand these challenging data.

The next crucial question is about the mechanisms of the observed protective effect of breast feeding, and how the introduction of formula milk may abrogate this protection. It is of considerable interest that the observed effects did not appear to be due to the reduction in the prevalence of respiratory infections, but only the babies' response to them. The authors confirmed the expected adverse effects on respiratory outcomes of several risk factors described previously, including maternal smoking and asthma, and late pre-term delivery [38-40]. However, they did not look for any effects of low birthweight and rapid weight gain [41], which may be one obvious way in which formula feeding may be contributing to respiratory symptoms.

There may be other potential mechanisms, which open potentially fruitful lines of enquiry. Studies in Amish and Hutterite communities provide fascinating evidence on how early environmental exposures can lead to key differences in the innate but not adaptive immune systems, and dramatically reduce the prevalence of asthma [42]. The present study has shown that exclusive breast feeding is not necessary for protection, but only the absence of formula feeding. So, is there some factor in formula milk that induces a switch of the innate immune system to a more pro-allergic condition? Or is it the loss of protective microbial exposure among formula-fed infants which can profoundly modify babies' immune responses at different levels? After all, it is the consumption of fresh raw cow's milk (yes, even in the first year of life) that is associated with strong protection against asthma and allergies among children growing up on farms [43]. Does this give us 
further clues to the pathways involved and more hope of modulating them, than just sending pregnant women off in droves to deliver their babies in stables (although the historical precedent for this is celebrated annually by many)? Is the situation now ripe for intervention studies in humans, and innovative studies in a neonatal animal model (although perhaps formula feeding mouse pups could be a challenge to even the most determined investigator) [44]?

The public health implications are stark. The extent of use of formula feeds described in this study is nothing short of a disgrace. Although it is clear that there are some women who cannot breast feed for the best of medical reasons, for example HIV infection, and therefore perforce have to use formula feeds, there is no reason at all why more than half these mothers did not breast feed for more than a year. Those nurses, midwives, health visitors and primary care paediatricians who are responsible for the care of babies need to take a long hard look at themselves and ask why their promotion of breast feeding is such a failure. Women with asthma need to understand the benefits to their child of avoiding formula milk. Would it be too radical to suggest formula milk should be made prescription only for children of asthmatic mothers? Perhaps, but something needs to be done; and that effectively and soon.

In summary, we are currently heading for a respiratory Armageddon of COPD deaths. The urgency of tackling this tsunami of death is only matched by the utter feebleness and complacency of our public health responses. If the tide is to be turned, it must be turned early in life, even antenatally. We need a "Right from the Start" programme for lungs (http://right-from-the-start.org/), with buy-in from all those responsible for the care of pregnant women and babies and children, as well as policy-makers. Smoking, e-cigarettes and environmental pollution must be tackled much more effectively, and the potential effects of formula feeds also highlighted. The CHILD investigators have done us a service by pointing out that breast feeding has its part to play in reducing infant morbidity, and the many long-term cohort studies all have the same message: if you are wrong from the start, you remain wrong forever. Of course, formula milk is not as sinister as nicotine, but nor is it as pure and innocent as the driven snow, and maybe it should carry a health warning for specific subgroups. Overall, the message is stark and clear - get it right in little lungs or it will go wrong and stay wrong in big ones.

\section{References}

1 Fletcher C, Peto R. The natural history of chronic airflow obstruction. Br Med J 1977; 1: 1645-1648.

2 Lange P, Celli B, Agusti A, et al. Lung-function trajectories leading to chronic obstructive pulmonary disease. N Engl J Med 2015; 373: 111-122.

3 Vestbo J, Edwards LD, Scanlon PD, et al. Changes in forced expiratory volume in 1 second over time in COPD. N Engl J Med 2011; 365: 1184-1192.

4 Casanova C, de Torres JP, Aguirre-Jaíme A, et al. The progression of chronic obstructive pulmonary disease is heterogeneous: the experience of the BODE cohort. Am J Respir Crit Care Med 2011; 184: 1015-1051.

5 Tagiyeva N, Devereux G, Fielding S, et al. Outcomes of childhood asthma and wheezy bronchitis. A 50-year cohort study. Am J Respir Crit Care Med 2016; 193: 23-30.

6 Tai A, Tran H, Roberts M, et al. The association between childhood asthma and adult chronic obstructive pulmonary disease. Thorax 2014; 69: 805-810.

7 McGeachie MJ, Yates KP, Zhou X, et al. Patterns of growth and decline in lung function in persistent childhood asthma. N Engl J Med 2016; 374: 1842-1852.

8 Berry CE, Billheimer D, Jenkins IC, et al. A distinct low lung function trajectory from childhood to the fourth decade of life. Am J Respir Crit Care Med 2016; 194: 607-612.

9 Curry BA, Blizzard CL, Schmidt MD, et al. Longitudinal associations of adiposity with adult lung function in the Childhood Determinants of Adult Health (CDAH) study. Obesity 2011; 19: 2069-2075.

10 Ramsay SE, Whincup PH, Lennon LT, et al. Longitudinal associations of socioeconomic position in childhood and adulthood with decline in lung function over 20 years: results from a population-based cohort of British men. Thorax 2011; 66: 1058-1064.

11 Bolton CE, Bush A, Hurst JR, et al. Lung consequences in adults born prematurely. Thorax 2015; 70: 574-580.

12 Devereux G, Tagiyeva N, Turner SW, et al. Early-life residential exposure to soil components in rural areas and childhood respiratory health and allergy. Sci Total Environ 2014; 466-467: 338-344.

13 Guilbert TW, Singh AM, Danov Z, et al. Decreased lung function after preschool wheezing rhinovirus illnesses in children at risk to develop asthma. J Allergy Clin Immunol 2011; 128: 532-538.

14 Tennant PW, Gibson GJ, Pearce MS. Lifecourse predictors of adult respiratory function: results from the Newcastle Thousand Families Study. Thorax 2008; 63: 823-830.

15 Svanes C, Sunyer J, Plana E, et al. Early life origins of chronic obstructive pulmonary disease. Thorax 2010; 65: $14-20$.

16 Li YF, Langholz B, Salam MT, et al. Maternal and grandmaternal smoking patterns are associated with early childhood asthma. Chest 2005; 127: 1232-1241.

17 Magnus MC, Håberg SE, Karlstad $\varnothing$, et al. Grandmother's smoking when pregnant with the mother and asthma in the grandchild: the Norwegian Mother and Child Cohort Study. Thorax 2015; 70: 237-243.

18 Haitchi HM, Powell RM, Shaw TJ, et al. ADAM33 expression in human lungs and asthmatic airways. Am Rev Respir Dis 2005; 171: 958-965.

19 Haitchi HM, Bassett DJP, Bucchieri F, et al. Induction of a disintegrin and metalloprotease 33 during embryonic lung development and the influence of IL-13 or maternal allergy. J Allergy Clin Immunol 2009; 124: 590-597.

20 Simpson A, Maniatis M, Jury F, et al. Polymorphisms in a disintegrin and metalloproteinase 33 (ADAM33) predict impaired early lung function. Am Rev Respir Crit Care Med 2005; 172: 55-60. 
21 Lee J-Y, Park S-W, Chang HK, et al. A disintegrin and metalloproteinase 33 protein in patients with asthma: relevance to airflow limitation. Am J Respir Crit Care Med 2006; 173: 729-735.

22 Simpson A, Custovic A, Tepper R, et al. Genetic variation in vascular endothelial growth factor-A and lung function. Am J Respir Crit Care Med 2012; 185: 1197-1204.

23 Banderali G, Martelli A, Landi M, et al. Short and long term health effects of parental tobacco smoking during pregnancy and lactation: a descriptive review. J Transl Med 2015; 13: 327.

24 Bush A. Lung development and aging. Ann Am Thorac Soc 2016; 13: Suppl. 5, S438-S446.

25 Bisgaard H, Jensen SM, Bønnelykke K. Interaction between asthma and lung function growth in early life. Am J Respir Crit Care Med 2012; 185: 1183-1189.

26 Saglani S, Malmström K, Pelkonen AS, et al. Airway remodeling and inflammation in symptomatic infants with reversible airflow obstruction. Am J Respir Crit Care Med 2005; 171: 722-727.

27 Guilbert TW, Morgan WJ, Zeiger RS, et al. Long-term inhaled corticosteroids in preschool children at high risk for asthma. N Engl J Med 2006; 354: 1985-1997.

28 Bisgaard $\mathrm{H}$, Hermansen $\mathrm{MN}$, Loland L, et al. Intermittent inhaled corticosteroids in infants with episodic wheezing. N Engl J Med 2006; 354: 1998-2005.

29 Murray CS, Woodcock A, Langley SJ, et al. Secondary prevention of asthma by the use of Inhaled Fluticasone propionate in Wheezy INfants (IFWIN): double-blind, randomised, controlled study. Lancet 2006; 368: 754-762.

30 Azad M, Vehling L, Lu Z, et al. Breastfeeding, maternal asthma, and wheezing in the first year of life: a longitudinal birth cohort study. Eur Respir J 2017; 49: 1602019.

31 Looijmans-van den Akker I, van Luijn K, Verheij T. Overdiagnosis of asthma in children in primary care: a retrospective analysis. Br J Gen Pract 2016; 66: e152-e157.

32 Martin MJ, Wilson E, Gerrard-Tarpey W, et al. The utility of exhaled nitric oxide in patients with suspected asthma. Thorax 2016; 71: 562-564.

33 Cane RS, Raganathan SC, McKenzie SA. What do parents of wheezy children understand by "wheeze"? Arch Dis Child 2000; 82: 327-332.

34 Cane RS, McKenzie SA. Parents' interpretations of children's respiratory symptoms on video. Arch Dis Child 2001; 84: 31-34.

35 Saglani S, McKenzie SA, Bush A, et al. A video questionnaire identifies upper airway abnormalities in pre-school children with reported wheeze. Arch Dis Child 2005; 90: 961-964.

36 Levy ML, Godfrey S, Irving CS, et al. Wheeze detection in infants and pre-school children: recordings versus assessment of physician and parent. J Asthma 2004; 41: 845-853.

37 Mallol J, García-Marcos L, Solé D, et al. International prevalence of recurrent wheezing during the first year of life: variability, treatment patterns and use of health resources. Thorax 2010; 65: 1004-1009.

38 Kotecha SJ, Watkins WJ, Paranjothy S, et al. Effect of late preterm birth on longitudinal lung spirometry in school age children and adolescents. Thorax 2012; 67: 54-61.

39 Harju M, Keski-Nisula L, Georgiadis L, et al. The burden of childhood asthma and late preterm and early term births. J Pediatr 2014; 164: 295-299.

40 Vogt H, Lindstrom K, Brabak L, et al. Preterm birth and inhaled corticosteroid use in 6- to 19-year-olds: a Swedish national cohort study. Pediatrics 2011; 127: 1052-1059.

41 Sonnenschein-van der Voort AM, Arends LR, de Jongste JC, et al. Preterm birth, infant weight gain, and childhood asthma risk: a meta-analysis of 147,000 European children. J Allergy Clin Immunol 2014; 133: 1317-1329.

42 Stein MM, Hrusch CL, Gozdz J, et al. Innate immunity and asthma risk in Amish and Hutterite farm children. N Engl J Med 2016; 375: 411-421.

43 von Mutius E, Vercelli D. Farm living: effects on childhood asthma and allergy. Nat Rev Immunol 2010; 10: 861-868.

44 Saglani S, Mathie SA, Gregory LG, et al. Pathophysiological features of asthma develop in parallel in house dust mite-exposed neonatal mice. Am J Respir Cell Mol Biol 2009; 41: 281-289. 